\title{
ORIGEN, DESARROLLO Y PROBLEMÁTICA ESPACIAL DE LA CIUDAD DE ALICANTE ${ }^{1}$ \\ Antonio Ramos Hidalgo
}

\begin{abstract}
RESUMEN
Se analiza el desarrollo de la ciudad de Alicante desde la época islámica hasta el presente, describiendo los principales procesos de urbanización generados en la misma y que son la causa de su actual configuración radiocéntrica.

El modelo de gestión urbanística ha producido disfunciones, perceptibles en la distribución residencial de la población, en los usos del suelo y en la calidad del entorno que diversos planes de reforma tratan de paliar.

La articulación de Alicante con su ámbito territorial consolida características metropolitanas, entre las que destacan un conjunto de variables de aglomeración relativas a población, vivienda, infraestructuras, actividades económicas y flujos de relación. La problemática analizada permite exponer un conjunto de consideraciones finales orientadas a futuras actuaciones de ordenación que afecten a la propia ciudad o a su espacio metropolitano.
\end{abstract}

\section{ABSTRACT}

This paper analyzes the development of the city of Alicante from the Islamic period to the present by describing the main urbanization processes that have occurred in the area and which are responsible for its present radial configuration.

As a result of the handling of the means of city management, certain dysfunctions have arisen, notably in the distribution patterns of housing, the use of land and the quality of the environment. A number of planned reforms have been conceived to deal with these problems.

The links between the city and its catchment area has led to the consolidation of metropolitan features, the most important of which are a series of variables affecting population, housing, infrastructures, economic activities and relation flows. Our analysis of these problems allows us to draw up a set of final considerations providing guidance for future arrangements affecting the city itself or its metropolitan area.

\section{PALABRAS CLAVE}

Alicante. Evolución urbana. Planeamiento urbano. Área metropolitana. 
En la ladera meridional del Benacantil fue donde el Alicante islámico, continuador de Lucentum, municipio latino, constituía un reducido recinto, esencialmente coincidente con el área del actual barrio de Vila Vella, al que una alcazaba otorgaba protección y en el que, pese a sus escasas dimensiones, se sustentaba una organización urbana en la que no faltaba muralla, mezquita, baños, hornos, ni zoco, así como manifiesta diligencia en la actividad de su puerto.

Tras la Conquista, la llegada de pobladores tuvo unas repercusiones decisivas para la ciudad, que se evidenciaron en la creación de nuevos espacios constituidos para la instalación de los recién llegados. Para la edificación de la llamada Vila Nova de Alicante se prefirió el llano costero, limitado por el barranco sobre al que en nuestros días se alza la Avenida de Méndez Núñez -la Rambla-, que potenciaría a su vez el aspecto defensivo de la ciudad cuando se edificara sobre él la necesaria muralla a la que serviría de foso, constituyendo el límite urbano hasta el siglo XVI. En este nuevo espacio construido crecería el caserío, abriéndose nuevas calles como la de Labradores y la Mayor, al final de la cual se alzaba la puerta de salida al camino de Elche. Algunas de estas calles supondrían la incorporación urbana de ciertos caminos, de extramuros en la ciudad musulmana, como la carrera de Elche o el camino de la huerta de Sueca, situada al W, en las cercanías de la ciudad, que aseguraban la articulación de la nueva trama urbana.

A resultas de ello, la vila nova se configuró al modo de las ciudades medievales de nueva fundación, con una trama ortogonal en la que destacan los ejes principales de las dos calles antes mencionadas, la de Labradores, con dirección meridiana y la Mayor, perpendicular a aquella. Éstas y sus complementarias presentan un trazado geométrico diferente del que puede observarse en la ciudad musulmana, más adaptado a la topografía del cerro.

La singular importancia que durante la Edad Moderna alcanzó Alicante, permitió su definitiva consolidación urbana tras la cuidada protección defensiva que animaría el establecimiento de comerciantes, órdenes religiosas y una colonia de ligures, afincados gracias al importante comercio de lanas castellanas, ampliado posteriormente con los productos coloniales americanos. Todo ello favoreció la ampliación del casco urbano y la creación de los nuevos arrabales de San Francisco y de San Antón, de comerciantes y marineros el primero, de agricultores el segundo y también la construcción de nuevas defensas que permitieron ampliar el solar de la ciudad hacia el muelle. Dentro de su recinto, el crecimiento poblacional y el auge económico hicieron precisa la edificación de viviendas y otras construcciones, sobre todo de tipo conventual. En efecto, a partir del primer tercio del siglo XVI se edifican la casa del Concejo, la capilla de la Purísima en la iglesia de Santa María y se fundan los conventos de Agustinos, Carmelitas, Dominicas, Monjas de la Sangre, etc., y se construye palacios, la Casa Asegurada, el Alfolí de la sal, la nueva planta del castillo y, fuera de la ciudad el pantano de Tibi.

Bombardeada por la escuadra francesa en el reinado de Carlos II, la Guerra de Sucesión dejó la ciudad en estado ruinoso, pero pronto recuperaría el carácter mercantil atrayendo numerosas representaciones consulares al concedérsele libertad de comercio con América. El siglo XVIII comporta una manifiesta prosperidad urbana, de la que permanecen importantes realizaciones arquitectónicas: fachada de Santa María, Ayuntamiento y Casa de Beneficencia. El crecimiento de Alicante hizo necesario el derribo de la antigua muralla y la construcción de un muro para cercar el arrabal de San Francisco. Fruto del desarrollo material de la ciudad a lo largo de este espléndido siglo son también algunos edificios de las calles Maldonado, Mayor, Labradores, M. Soler y Gravina.

Al inicio del siglo XIX se construye el Barrio Nuevo y con posterioridad se desencadena el más significativo proceso de cambio y replanteamiento urbano conocido hasta el momento en la ciudad. La incapacidad del recinto murado, la escasez de suelo y viviendas en 
el interior del mismo y la precariedad de sus viales impulsó la remodelación de la trama urbana existente, así como la creación de un proyecto de Ensanche de ambiciones más que medianas. La necesidad higienista de la época, por su parte, animó la creación del barrio de Benalúa.

El aumento de infraestructuras que ocasionaron la construcción del ferrocarril y el progresivo desarrollo del puerto, las coyunturales favorables del comercio, la concesión de la categoría de capital provincial y la multiplicación de funciones derivadas de la misma, dinamizaron este proceso. No obstante, la falta de recursos privados y las limitaciones ordenancistas en el área del Ensanche, motivaron la expansión de la ciudad, en buena medida, al margen del mismo a lo largo del siglo XX. Por ello surgirían cada vez más vigorosamente en el extrarradio de la ciudad, aprovechando las vías de comunicación, una serie de zonas suburbiales, carentes de los mínimos servicios. Estas áreas urbanizadas se abren hacia la periferia generando una disposición en abanico que inicia el modelo radial, según el cual la ciudad crecerá, en oleadas sucesivas más allá de donde acaba el perímetro anterior. Hacia el norte, por Altozano, Los Ángeles, San Agustín y Ciudad Jardín; hacia el este por el Barrio Obrero, Vistahermosa y las colonias de El Pla; al sur, por el Barrio de Industrias Textiles y San Gabriel, y al oeste, alrededor del Portazgo, fue estructurándose el barrio de la Florida.

A consecuencia del impulso demográfico de los últimos treinta años, se ha ido desarrollando otra nueva serie de sectores urbanos, las más de las veces inconexos entre sí y alejados también del centro de la ciudad, cuya finalidad era paliar el real déficit de viviendas que presentaba la ciudad.

Distintas promociones, con diferencias de planteamiento, diseño, calidad y objetivos se han ido edificando desde entonces. Acometidas inicialmente por el sector público, éste, paulatinamente ha sido sustituido por la iniciativa privada, que se ha beneficiado de todo tipo de ventajas operativas, fiscales y crediticias. Ello ha ocurrido fundamentalmente a partir del inicio de la década de los sesenta, momento en que va a desarrollarse un amplio proceso de edificación, escasamente ligado a las directrices del Plan General de Ordenación, que se caracteriza por sus bajos niveles dotacionales, así como por densidades poblacionales muy elevadas, causantes de dificultades organizativas de la ciudad de nuestros días, con la que se vincularán las nuevas barriadas a través de las carreteras que convergen a ella. Surgen, de este modo, una serie de núcleos aislados, amparados en el bajo precio del suelo en la periferia y al margen de la dinámica de crecimiento de una ciudad que apenas consigue englobarlos en su propia trama consolidada.

Entre los polígonos y barrios a los que nos hemos referido se encuentra el barrio de Montoto, del quinto de este siglo. De la misma época es el barrio de la Sagrada Familia, la Ciudad de Asís y la barriada de la División Azul. Más recientes son los de Mil viviendas y otros que pueden añadirse dada la similitud de características: Divina Pastora, Requena, Juan XXIII y la gigantesca Virgen del Remedio. Posteriores a esto y claramente diferenciadas en sus aspectos económicos y sociales son las promociones de Alipark, El Palmeral y las asentadas en los polígonos de San Blas, Babel y Playa de San Juan.

A consecuencia de ello la ciudad presenta en la actualidad una serie de limitaciones, difícilmente paliables, en relación al tráfico, al equipamiento dotacional y a la accesibilidad del centro. El último Plan General de Ordenación Urbana, recientemente aprobado, pretende atenuar el lastre de anteriores actuaciones y canalizar la realización de proyectos diseñados por el desarrollismo de anteriores épocas, intentando acomodar las realizaciones imprescindibles a las necesidades más urgentes. 


\section{El paisaje urbano}

El crecimiento urbano descrito, ha configurado en los cuatro últimos decenios, de una parte, una ciudad marcadamente radiocéntrica, que ocupa en la actualidad una superficie superior a las 1.000 Has, en la que las carreteras que a ella acceden han servido de ejes nucleadores de las nuevas barriadas; de otra parte, en las costas NE se ha edificado un

segundo conjunto urbano de gran importancia justificado no sólo por su primitivo uso veraniego, sino también, recientemente, por un claro cambio de mentalidad en los hábitos residenciales, facilitado por la localización en esa zona de una oferta inmobiliaria muy tipificada.

La ciudad establece la relación entre su núcleo genético y las mencionadas barriadas periféricas, ordenadas en torno a las carreteras de acceso, mediante una zona en la que se ubica el ensanche decimonónico, que envuelve el otro recinto amurallado de la ciudad histórica y sus arrabales. La trama de esta última área urbana está formada por diversos barrios, legado de la ciudad tradicional, que desde las vertientes del Cerro Benacantil se extienden hacia el llano costero en una extensión de 41'3 Has. De ellas 18'6 Has corresponden al recinto más antiguo, ocupado actualmente por los barrios de Santa Cruz, Carmen, San Roque, Villavieja, instalados sobre las vertientes del cerro, y los de San Nicolás y Ayuntamiento, a más baja cota y en dirección al mar. El arrabal de San Francisco por su parte, ocupa 15'18 Has, en tanto que el llamado Barrio Nuevo tan sólo 7'5 Has. El total de las superficies mencionadas se completan con las 10 Has del Arrabal de San Antón y las 1'5 Has del Arrabal Roig.

Los barrios situados a cota superior ofrecen, aparte de su diversidad topográfica y riqueza de perspectivas, resultado de su localización, una secuencia de plazas y recintos en los que el espacio público no está todavía privatizado, encontrándose en su entorno los últimos restos locales de la arquitectura mediterránea, a la que se ha querido atribuir carácter de típica, en consideración a la apariencia del conjunto.

Las áreas próximas al mar disponen de calles de recto trazado y uniforme ancho en toda su longitud. La variedad tipológica de este viario (medieval, renacentista y dieciochesco), además de la notable concentración de edificios de valor arquitectónico, histórico o ambiental, otorgan a esta unidad una excepcional importancia dentro del conjunto urbano actual.

Al W de la Rambla se sitúa el arrabal de San Francisco, antigua sede de comerciantes y marineros, que conserva en la actualidad un buen número de edificaciones neoclásicas, destinadas, en su origen, a residencia. Dicho conjunto a finales del siglo XIX experimentó una importante renovación arquitectónica que supuso una significativa ampliación tipológica de la vivienda burguesa, localizada, esencialmente, en plazas, la fachada costera o lindante con el Ensanche.

Frontero al arrabal se encuentra el Barrio Nuevo edificado a principios del siglo XIX alrededor de una plaza central, posee una trama neoclásica ortogonal de tal adecuación y ajustado diseño que su trazado y alineaciones han perdurado hasta nuestros días.

El Arrabal de San Antón, del siglo XVI, y que fue globalmente reconstruido en la segunda mitad del siglo XIX, enmarca sus límites en el perímetro comprendido entre la barroca Casa de Misericordia, el jardín romántico de Quijano y la vertiente NW del Benacantil. Su traza, netamente jerarquizada, acoge un modesto conjunto arquitectónico de tipología y características uniformes, que ha sufrido una intensa renovación en su franja exterior recayente a la calle de San Vicente. En este barrio han actuado con especial virulencia los procesos de degradación patrimonial referentes a la red viaria, servicios urbanos, equipamiento e, incluso, en la vivienda, donde han llegado a aparecer bortes de chabolismo.

Citamos, por último, el Arrabal Roig, situado ante la Puerta Nueva del Camino de 
Valencia y encajonado entre la abrupta ladera suroriental del Benacantil, la rambla de Bonivern y la playa. Pequeño reducto de origen medieval, a partir del siglo XVIII ocupa todo el terreno disponible y servía de lugar de residencia a pescadores. En la actualidad, no sólo es difícil reconocer su primitiva traza y característica función, sino, incluso lo que fue su peculiar ambiente. Las actuaciones sobre la calle Virgen del Socorro y la plaza de Topete han descompuesto y aislado el arrabal a causa de los gigantescos volúmenes edificatorios, cuya construcción se vio estimulada por su situación costera. Consecuentemente el barrio se ha degradado hasta el límite de lo irrecuperable.

El crecimiento reciente, por su parte, ha colmatado progresivamente áreas consolidadas y nuevos ensanches sucesivos, sin mejorar dotaciones, equipamientos ni las necesarias infraestructuras. El proceso ha aumentado así mismo el volumen edificable y la sistemática ocupación de espacios libres. De esta forma, en los bordes de contacto entre viejos y nuevos ensanches y polígonos la ciudad se muestra inacabada. Falta la sutura entre una y otra forma de entender la ciudad y se carece de tipologías edificatorias apropiadas para atenuar la brutalidad de forzadas yuxtaposiciones.

De esta forma la aparición de nuevos polígonos, configurados con ligeras variantes de bloques y la carencia de infraestructuras adecuadas, dejan sin solución el problema de la calle y de los lugares de relación.

Por otra parte el crecimiento en mancha de aceite fue dejando grandes vacíos entre los barrios, como fruto de una estrategia combinada consistente, en primer lugar, en ocupar el suelo más alejado y barato y, en segundo lugar, en revalorizar las áreas más cercanas al núcleo central. Estos espacios intersticiales muestran con toda su agudeza la ausencia de integración de las nuevas barriadas con la ciudad existente.

Digamos finalmente que este proceso urbanizador reciente, mera colonización de espacio, se ha efectuado bajo supuestos y promesas nunca cumplidas, animados por hipotéticas redes arteriales e infraestructuras básicas que nunca se han realizado y unos supuestos de equipamiento inexistentes.

\section{La gestión del espacio urbano y los planes de reforma}

En todo este conjunto, de indudable interés morfológico, organizativo y ambiental, se ha desarrollado en paralelo al último ciclo de crecimiento de la ciudad, un espectacular proceso de degradación que ha generado cambios en la fisonomía de su patrimonio arquitectónico y en los usos del suelo, afectando también a la estructura de la población residente, con desplazamientos significativos de la misma.

Importantes factores de tipo económico jugaron un papel decisivo en ello sin que su actuación fuera frenada desde la administración municipal, la cual, ante la pasividad ciudadana, colaboró también en ello, unas veces por la influencia de determinadas fuerzas económicas sobre la esfera política y otras actuando a favor de un desarrollismo vacío de sensibilidad.

Si con anterioridad a 1956 pueden detectarse algunas actuaciones que suponen una agresión para el centro histórico, es a partir de este momento cuando las mismas se multiplican al amparo de una normativa que el I P. G. O. U. impuso, al permitir sus ordenanzas en un primer momento la construcción de diez plantas en altura, once posteriormente, que duplicaban la autorizada en anterior normativa, y otorgaban la consideración de intensiva alta en el plano de zonificación a buena parte del núcleo tradicional, excepción hecha de un reducido sector del mismo, adosado al'Benacantil, y considerado como histórico-artístico. El sector contiguo a éste, atravesado por la Rambla de Méndez Núñez y definido 
como comercial, se beneficiaba de la accesibilidad que le otorgaban la Rambla mencionada, la Explanada de España y la avda. de Alfonso el Sabio. De esta forma se institucionalizaba en todo su valor el centro terciario comprendido entre este área, y la avda. de Soto-Gadea, límite, ésta última del Ensanche, sobre las que se abrieron enormes expectativas favorables a la especulación del suelo y el mercado inmobiliario.

A partir de este momento se acentúa su diferenciación con el primitivo núcleo urbano, en el que la pasividad y la carencia de actuaciones de protección han provocado el abandono y la destrucción paulatina de edificios y la consecuente marginación social. Todo esto ha llegado a configurar dicha zona como un área marginal sociológica y urbanística, cuando paradójicamente es un espacio urbano vecino al centro terciario.

Con el P. G. O. U. aprobado en 1973 se acentuaría todavía más la degradación del centro histórico; dado que aunque la nueva ordenanza limitara a 8 las alturas, en la práctica siguió produciéndose en el centro terciario el aumento de volúmenes construidos en las operaciones de renovación, so pretexto de la singularidad de los edificios.

Por otra parte, la consideración de verde público otorgada al conjunto de barrios situados a más alta cota en la ladera del cerro agravó el éxodo de la población residente y el aumento espectacular de casas ruinosas y solares al negar licencias de obra e impedir las reparaciones de edificios.

Durante el período de vigencia de estos planes se llevaron a cabo importantes operaciones de renovación en las vías principales, en las áreas de borde, en la fachada costera, Arrabal Roig y Sector Norte de la Rambla, con el consiguiente desalojo de los antiguos residentes y el acceso al área de sectores de la burguesía. La demanda e incorporación de mayor número de servicios, el necesario aumento de accesibilidad exigida por el automóvil y la presión de la periferia sobre el centro forzó la construcción de estacionamientos privados de vehículos en los límites del centro, sobre la ladera del Benacantil, en la plaza de la Montañeta y en las de San Cristóbal y Topete, donde su instalación privatizó e hizo desaparecer el ambiente propio de los recintos de las mismas.

Los mencionados procesos de renovación no afectaron al Arrabal de San Antón, al estar inmersos sus bordes meridional y oriental en el proyecto, aún hoy estancado, de la llamada Zona de remodelación. La suspensión temporal de licencias de obras y la subsiguiente falta de expectativas lo marginaría inicialmente de los circuitos especulativos del suelo urbano.

Por su parte, la reciente Adaptación del P. G. O. U., aprobado con fecha 27-III-87, decide hacer suyas las propuestas contenidas en los planes especiales a la vez que explicita dos propuestas de ganancia de accesibilidad al centro, mediante dos vías colectoras urbanas: Solución plaza de América y circunvalación Norte del Benacantil. Éstas facilitarían la remodelación del barrio de San Antón.

El trazado de dos vías de circunvalación (Gran Vía y Vía Parque), al descongestionar el tráfico que soporta la carretera nacional 330, permitiría recuperar la interrelación del Arrabal Roig con la costa.

El mismo plan contempla una inversión cuatrienal de 100.000.000 de pesetas para fomento de la renovación, al tiempo que detalla la mejora de dotaciones y la consiguiente creación de las necesarias.

Ante la descrita situación de progresivo deterioro, la Ley del Suelo de 1976 ofrece el instrumento jurídico adecuado para la protección del patrimonio histórico-artístico inmueble en su más amplia acepción; nos referimos a la figura del «Plan Especial». Su aplicación al caso de Alicante ha tenido como consecuencia el desarrollo de los cuatro planes que a continuación enumeramos junto a sus correspondientes redactores: «Plan Especial del Casco Histórico», de Miguel Ángel Cano, aprobado el 20-III-1981, del mismo es el «Plan 
Especial de Edificios Protegibles de la ciudad de Alicante», de 21-XII-1982. De Miguel Garulo Muñoz y Manuel Asín Castellón es el «Plan Especial de Reforma Interior. Raval Roig», de 18-XII-1982, y por último, de Mauricio Úbeda y el grupo PERI es el «Plan Especial de Reforma Interior. Barrio de San Antón, aprobado con fecha 27-II-1987, descritos en otro lugar por Ramos y Quiñonero.

Estos cuatro planes se justifican en función de las especiales características de los sectores urbanos sobre los que se aplican, ofreciendo en su conjunto propuestas bien diferenciadas adecuadas a la diferente tipología de los mencionados sectores.

El Plan Especial del Casco Histórico considera como tal el recinto murado anterior al siglo XVIII, no obstante afirma que su área de intervención debiera incluir asimismo, el espacio edificado más allá de la Rambla, con el que formaba una unidad, rota por la desafortunada prolongación de la Rambla de Méndez Núñez, que ha pasado a ser arteria principal de la ciudad, modificando su primitivo sentido de paseo que conectaba ambos sectores.

La necesidad de un plan especial para el área se justifica por la pérdida de su capacidad residencial y la notable disminución de sus actividades tradicionales; quedando, por tanto, muy disminuida su importancia en el conjunto de la ciudad. Acentúa esta situación la naturaleza de sus límites: la barrera natural del cerro Benacantil (fondo de perspectiva visual), la Rambla y la Avenida de Jovellanos y la de Lafora, paso de la carretera de Valencia, ambas arterias de primera categoría en el sistema circulatorio de la ciudad, que han ocasionado una terciarización incontrolada de sus bordes, considerados como zona intensiva alta en los sucesivos Planes Generales de Ordenación Urbana de la ciudad, originando una amenaza en sus zonas próximas, al romper el equilibrio existente en el sistema urbano anterior mediante la liquidación o postergación del uso residencial por otros.

Los objetivos básicos de solución que propugna el Plan Especial del Casco Histórico son los siguientes:

-Mantenimiento del área como órgano importante en el conjunto de la ciudad, facilitando su relación con el resto de la misma mediante la anulación de las barreras artificiales y la recuperación de su primordial carácter de residencia, favoreciéndolo mediante la peatonalización de grandes zonas y las actividades de relación, íntimamente ligadas a las residenciales.

-Restituir su equilibrio funcional y residencial, dado que como órgano de la ciudad deberá contener parte de sus actividades, si bien, limitadas a algunas zonas, evitando su museización.

-Mantenimiento de la estructura física, que se traduce en una potencialización de la vivienda, política de saneamiento y mejora de las condiciones de habitabilidad.

-Preservación de los elementos arquitectónicos y urbanos de valor singular y ambiental, tanto de la edificación (edificios significativos o los que en sí mismos son poco importantes, pero dan una imagen de conjunto a proteger), como de la trama urbana (la protección del tejido viario se basa fundamentalmente en no sobrepasar la capacidad para la que fue creada, con la conservación a ultranza de todo el tejido viario y máxima peatonalización.

Subraya, por último, la importancia que tiene la lógica conservación de la relación continente (edificio)-contenido (población).

El Plan Especial de Edificios Protegibles de la ciudad de Alicante tiene como finalidad la necesidad de conservar, restaurar y potenciar el patrimonio cultural-urbano de la ciudad, entendiendo por tal tanto los elementos y conjunto edificatorios de interés, como los ambientes y estructuras urbanas especialmente significativas, incluyendo los elementos singulares que los conforman, ya sean vegetales, escultóricos o simplemente definitorios 
de texturas superficiales. Esta necesidad deriva del fuerte dinamismo y ritmo de crecimiento de la ciudad, que han quedado patentes en la expansión alcanzada durante los últimos años.

En este Plan Especial se engloba un análisis sistemático y exhaustivo de los valores patrimoniales existentes, no protegidos o en vías de protección a través de otros instrumentos de ordenación territorial, y se plantean soluciones eficaces tendentes a la conservación de los elementos singulares o ambientales considerados de interés.

Sin embargo, y en opinión de su autor, el alcance de este Plan se encuentra limitado por el propio carácter puntual del mismo, y así no puede ir más allá de establecer unas medidas cautelares específicas, que se benefician de la actuación gestora y subvención municipales. Una acción de este tipo carece de fuerza necesaria para evitar la degradación del patrimonio y se muestra incapaz de conseguir una rehabilitación integral del patrimonio edificado de la ciudad.

En resumen, las metas perseguidas por este Plan son: conservación integral de los valores histórico, artístico o estético, una vez realizada la enumeración exhaustiva de los bienes protegibles; conservación dinámica que engloba la gestión continua del Plan y la revitalización del patrimonio; minimización de los costes sociales con lo que se pretende alcanzar un equilibrio entre la acción conservadora y los intereses más directamente afectados, entre los que se incluye la necesaria dinámica evolutiva de la ciudad; maximización de los rendimientos de las inversiones públicas y, por último, la adecuación de sus objetivos a los del Plan General.

Plan Especial de Reforma Interior. Raval Roig: La serie de actuaciones urbanísticas en el entorno del Arrabal Roig han causado un grave perjuicio, de carácter irreversible, a su identidad y personalidad tradicionales, en tanto que el área residual del antiguo conjunto soporta un alto grado de deterioro, producido por el impacto ocasionado por la construcción de tendidos ferroviarios y carreteras (nudo de comunicaciones con pasos a distinto nivel y seis carriles de tráfico con mediana).

El área afectada por el Plan Especial es de $8.760 \mathrm{~m}^{2}$, lo que supone una disminución de la superficie primitiva del barrio al excluir la superficie ocupada por las intervenciones de renovación allí efectuadas, de manera que los restos del antiguo arrabal, prácticamente, son una reliquia de una organización urbana desaparecida.

El objetivo de este Plan es la recuperación del significado ambiental e histórico que aún conserva, dentro de una política urbanística de conservación de los valores significativos de la ciudad; entendiendo que el parcelario existente en el barrio constituye un claro elemento definitorio de la trama urbana heredada, y que debe ser asumida en la ordenación. Resultando todo este conjunto de medidas indispensable para posibilitar la renovación sin operaciones de transferencia de propiedad, armonizando de esta manera la recuperación del patrimonio colectivo con los legítimos derechos de los diferentes propietarios particulares.

Plan Especial de Reforma Interior. Barrio de San Antón: Ante la situación de crisis y abandono, presente en el barrio, su Plan Especial tiende a recuperar su imagen tradicional, evitando o paliando la rotura del equilibrio que en dos de sus zonas se ha producido en el mismo, de forma incontrolada; así, en la zona recayente al centro de la ciudad se ha generado un proceso especulativo, con edificación en altura, que oculta el resto del barrio, así como un proceso de terciarización abusiva que daña su propia economía interna; mientras que en los aledaños de la ladera del Benacantil es producido un proceso de ruina y demolición de viviendas.

Por ello, la justificación del carácter del Plan Especial estriba en la necesidad de una actuación integrada, cuya finalidad sea la solución de sus problemas: saneamiento, mejora del medio ambiente y creación de equipamiento comunitario o de intencionalidad para la 
relación social, con el consiguiente mantenimiento de la identidad y significado del barrio en el contexto de la ciudad. Además, partiendo de la defensa de la trama, sugiere desarrollar un proceso de renovación destinado a hacer prioritaria la actividad residencial y mejorar la estructura social existente.

Otros objetivos contemplados en el Plan son: la integración de la estructura del barrio en su entorno, facilitando la transición entre éste y el resto de la ciudad, la recuperación de su imagen, el mantenimiento de la vida social espontánea mediante la construcción de una red de espacios públicos y la consiguiente implantación de funciones internas al barrio, y de actividades artesanales y de ocio. Igualmente pretende conseguir la accesibilidad al castillo de Santa Bárbara mediante vías peatonales.

Pese a la normativa contenida en estos planes su aplicación no ha producido ni las suficientes ni las necesarias manifestaciones reactivadoras capaces de mejorar globalmente la situación. Los procesos de rehabilitación y de renovación apenas interesan a la promoción privada y los organismos públicos adoptan ante ellos una actitud de pasividad. De esta forma, antes que consolidarse determinados efectos regeneradores de carácter social o espacial puede apreciarse en la actualidad el alto nivel de degradación que sufre el centro histórico.

No obstante, aunque persisten los problemas y siguen actuando negativamente las estrategias de los agentes urbanos comienza a percibirse recientemente un cierto cambio de actitud, que tiene reflejo en la veintena de realizaciones puntuales llevadas a cabo por organismos públicos e instituciones financieras. En esta misma línea, y acogiéndose a las bases reguladoras de medidas de fomento para la rehabilitación del patrimonio edilicio la iniciativa particular ha consumido, en otra veintena de edificios, tan sólo la cuarta parte de los 30.000.000 de pesetas presupuestados para tal fin en el último trienio.

Asimismo, el estudio y creación de nuevas vías peatonales, la apertura de centros comerciales de frecuentación diaria y las agrupaciones de comerciantes por calles pueden ser, igualmente, indicios de cierta recuperación; aunque resultará difícil la competencia con los centros comerciales de gran superficie existentes en la periferia, a los que se ha sumado otro, que disminuirán sensiblemente el uso del espacio terciario tradicional, desplazando, irreversiblemente el centro hacia el oeste.

De cualquier manera resulta evidente que es preciso, tras la necesaria creación de los correspondientes organismos de gestión y sus necesarios mecanismos financieros, acrecentar el patrimonio municipal, dotándole de la correspondiente infraestructura administrativa de la que hoy carece; fomentar la instalación de sedes oficiales y residencias particulares; impulsar la construcción de viviendas subvencionadas, así como exigir a sus propietarios la rehabilitación de antiguas casonas con derecho a exenciones fiscales.

\section{Los procesos de metrapolitanización}

Una visión diacrónica de la organización territorial de ámbito meridional del País Valenciano permite constatar la aparición, en estos territorios, de características metropolitanas entre las que destacan como factores básicos ciertas variables de aglomeración metropolitana. Por un lado las relativas a población, vivienda, territorio...; en tanto que por otro destaca así mismo un sistema de infraestructuras: carreteras, puertos, aeropuerto,... y por último ciertas secuencias de flujos metropolitanos: actividades y desplazamientos de trabajo, residenciales y de ocio.

En relación con el primer factor, los criterios delimitativos, tanto españoles como internacionales, consideran aceptable la delimitación metropolitana cuando las cifras de 
población superan los 400.000 habitantes asentados en un territorio cuya densidad poblacional supere los 100 habs. $/ \mathrm{Km}^{2}$ y su ciudad central tenga más de 200.000 habitantes, a la vez que exista continuidad territorial entre los municipios que la componen.

El segundo criterio valora el grado de comunicación existente entre las distintas partes del organismo. Por sí solas, las unidades de población, sus actividades y carácter residencial, no valoran un área metropolitana. La necesaria intercomunicación precisa de infraestructuras capaces de articular un territorio entre sí y con el exterior. Por ello, la distancia o el tiempo necesario para el desplazamiento desde el centro del área al borde de la misma debería suponer costes asumibles para los imprescindibles flujos trabajo-residencia, residencia-ocio, residencia-compras, etc., fundamental componente interno autoconsumidor, pero sin olvidar las necesidades de rápida comunicación con el exterior del área: aeropuerto, puerto y autopistas.

La difusión de flujos, por su parte, se debe no exclusivamente a actividades meramente locales, sino que su localización aprovecha un preciso grado de rentabilidad sobre el espacio. Los espacios centrales han sido ocupados sistemáticamente por las actividades económicas del sector terciario: financiero, administrativo, comercial, que han expulsado hacia las periferias las producciones del sector secundario y a la población residencial. De esta forma, el espacio metropolitano alcanza rangos superiores de transformación, y ésta, más compleja que la exclusivamente local.

El área metropolitana que se perfila presenta ciertas características peculiares, entre las que cobra singular importancia el hecho de que se hayan configurado dos subáreas, una es la de Alicante y su mancomunidad: San Juan, Campello, San Vicente del Raspeig y Muchamiel; y la otra es la formada por Elche, Crevillente y Santa Pola.

No obstante, las principales variables de población, urbanismo e infraestructuras -obviamente por debajo de los mínimos convenientes en carreteras- y flujos son suficientemente explícitos en cuanto a la configuración del área. Existe una vitalidad económica, sociológica y urbanística que configura, más allá de un estático sistema de ciudades independientes, un continuum urbano manifiesto.

La población supera los 623 habs. $/ \mathrm{Km}^{2}$, y sus ritmos de crecimiento manifiestan un dinamismo no polarizado. Antes al contrario, un característico sistema de difusión desarrolla en la provincia ritmos de crecimiento superiores a los de otras áreas metropolitanas españolas.

Dicha dinámica se ha beneficiado de una infraestructura insuficiente y anticuada, pero ventajosa respecto a la de otras áreas. Un aeropuerto internacional, equidistante de los dos núcleos mayores núcleos urbanos de la zona, un puerto terminal, el paso de RENFE y el cruce de la autopista con tres carreteras nacionales, (C. N. 330, C. N. 332 y C. N. 340), además de la autovía en construcción, que con otras de servicio local y comarcal expresan el valor de dichas infraestructuras para el asentamiento económico.

La diferente orientación económica de actividades y flujos ha determinado así mismo el carácter de la aglomeración, rompiendo la estructura radioconcéntrica y jerarquizada habitual de las áreas metropolitanas y dando origen a otra bipolar y complementaria. Alicante se orienta hacia el terciario y las actividades turísticas, con el contrapeso industrial de San Vicente y el agrario de Muchamiel, en tanto que la de Elche se especializa en actividades industriales, con Santa Pola diversificada hacia el turismo y el ocio.

En esta estructura territorial los flujos trabajo/residencia, residencia-ocio o residencia-compras corroboran el anterior aserto, no siendo aún especialmente significativo el flujo Alicante-Elche.

Dada la envergadura económica del área metropolitana y el volumen de sus importantes presupuestos municipales, así como el de los respectivos niveles de inversión, parece necesario abordar la forma metropolitana la resolución de los problemas municipales que, 
reiterados por separado, son comunes al área. De ese modo, las inversiones de otros organismos en infraestructuras: costas, carreteras, aeropuerto, puertos, RENFE, depuradoras, etc. gozarían de una más eficiente incorporación al sistema de equipamientos metropolitanos.

Por lo que respecta a la ordenación urbana debe insistirse en el singular papel director que los Planes Generales de Ordenación Urbana tendrán que desempeñar para asegurar el futuro de la evolución prevista a corto plazo. No se trata únicamente de que las oficinas municipales correspondientes se preocupen por lograr la ejecución de sus propias propuestas, establecidas con el fin de acabar con las respectivas insuficiencias urbanas. En cualquier caso, la tarea al respecto es ingente dado el ambicioso conjunto de intenciones reglamentistas que los textos de los Planes recogen, los planes de etapas comprometidos y la enorme cuantía de sus exigencias financieras, sobre las que necesariamente habrá de gravitar el cumplimiento de sus previsiones.

Será preciso que las directrices emanadas de cada Plan coincidan armónicamente, y con la flexibilidad necesaria, con los agentes públicos y la iniciativa privada, cuyas actuaciones serán necesarias en el crecimiento de las ciudades. En el caso de Alicante, parece que cobran extraordinaria importancia los proyectos de ampliación de oferta inmobiliaria y turística de los sectores costeros de Playa de San Juan y Urbanova-Arenales del Sol, mediante diversos Planes de Actuación Urbanística.

En el primer caso, la iniciativa de ciertos grupos financieros y de promoción local pretenden la edificación de un gigantesco complejo residencial, deportivo y de ocio, con una notable remodelación del área que incluye el desvío del ferrocarril costero, con instalaciones de alta calidad, entre las que se incluyen parque acuático, campo de golf, estadio olímpico, palacio de exposiciones y la consiguiente panoplia de instalaciones complementarias. El complejo incluye varios millares de nuevas viviendas, con un volumen de inversión de decenas de millares de millones de pesetas.

En conjunto esta obra podría suponer un grave problema añadido a los que Alicante arrastra en aspectos tales como el abastecimiento de agua, la disponibilidad de infraestructuras viarias, o la localización del esfuerzo constructor en un espacio tan problemático como el costero, en el que, sin duda, se ha superado la capacidad de uso del suelo y en el que se experimenta un notable grado de saturación del ecosistema de la franja costera. Ello, sin duda, dificultará el proceso físico de conexión metropolitana con Elche y retrasará la necesaria compactación de los actuales huecos del tejido urbano consolidado.

Dicha disyuntiva no debe ser obstáculo a la evidente canalización de capital inmobiliario hacia la zona, en fuerte incremento desde la adhesión a la C. E. E., ni tampoco debe impedir el necesario robustecimiento del papel director que en el territorio provincial debe desempeñar su capital.

Por su parte, en el extremo sur del municipio se proyecta en áreas declaradas como no urbanizables en el P. G. O. U. otro conjunto residencial, de características similares al anterior. Para este caso siguen siendo válidas las anteriores consideraciones, matizadas en el sentido de que la realización del proyecto supondría afianzar las interrelaciones Alicante-Elche en su aspiración metropolitana y, aunque se instalase sobre un espacio de interés ecológico y científico, este sector costero está muy lejos de alcanzar los niveles de saturación del correspondiente a la playa de San Juan y del mismo podría derivarse el beneficio añadido de la mejora en las comunicaciones hacia el sur provincial.

Para finalizar estas consideraciones indicamos que sería necesario establecer los oportunos controles para que del conjunto de ambos proyectos no se derive opciones exclusivamente elitistas al alcance tan sólo de algunos y para que la dinámica que generen ambos conjuntos no vaya en detrimento del carácter viviencialmente globalizador al que debe aspirar todo organismo urbano.

\section{Propuestas}

Consideramos necesario, después de lo que llevamos expuesto, realizar una serie de 
consideraciones y propuestas. Adoptaremos en las mismas una actitud positivamente constructiva a la luz de lo que dictan las tendencias observadas a nivel general en la sociedad española actual y, a nivel particular, en los rasgos propios de la situación alicantina.

En relación con los procesos de evolución de la ciudad la primera propuesta que establecemos es aquélla que considera que debe superarse el concepto actual de que el urbanismo, nuestras ciudades, y en particular Alicante, están en crisis.

En segundo lugar hay que abandonar un debate, asfixiante por su monotonía, en el que no cesa de reiterarse que la ciudad heredada es la imagen de la ciudad en la que los actuales habitantes querrían vivir y en la cual los actuales instrumentos legales e institucionales heredados son incapaces de abordar los problemas urbanos ni tampoco permiten dotar de los recursos económicos, administrativos y humanos necesarios para resolverlos.

Por otra parte hay que abordar los efectos e impactos de la crisis económica actual dado que ella desciende los niveles de actividad, tanto en demanda como en producción de bienes y servicios de naturaleza urbana, pero sobre todo porque afecta a la esencia misma de la vida urbana.

Por ello, el punto de partida debe considerar la lógica que presidió el enorme proceso de expansión descrito en el que un urbanismo «de frontera» auspiciado por la Ley del Suelo desarrollista debe ceder paso a una acción pública basada en criterios de austeridad y contención que procure recuperar la ciudad, rehabilitando y reequipando los centros urbanos y las nuevas áreas consolidadas, valorando, los hasta ahora casi inexistentes, valores ambientales, la estética urbana y la calidad de la vida.

En cuanto al patrimonio urbano debe llevarse a cabo un cabal cumplimento de cuantas propuestas plantea el P. G. O. U. y los Planes especiales vigentes, de los que ya hemos valorado su grado de intervención, sin permitir el deterioro progresivo del centro histórico, su congestión de tráfico ni la pérdida o destrucción de sus elementos patrimoniales, sustituidos, las más de las veces, con triviales criterios.

Debe procurarse, en las renovaciones de uso requeridas, atenuar la pérdida de entidad y el subsiguiente desplazamiento del centro mediante una eficaz utilización de los contenedores arquitectónicos.

En la periferia hay que plantear una adecuada política de equipamientos cualitativos y de ajustada localización. Es preciso también desarrollar ejes peatonales en las barriadas, en las que la congestión es así mismo intensa y generar subcentros de equipamiento que disminuyan su relativo desequilibrio actual. Por ello deberían localizarse aquí buena parte de las nuevas dotaciones de uso urbano general, a fin de consolidar en las mismas calidades de vida de las que en la actualidad se carece e intentar la construcción de viales -tipo rambla mediterránea- tan adecuados en nuestro ambiente.

Habría que procurar que los agentes públicos evitasen conocidos errores técnicos, imprudencias jurídicas y pasos en falso, dada la precariedad de instrumentos que la Ley del Suelo dota a las corporaciones para la intervención en el continuo urbano.

Así mismo debería ajustarse la realidad económica financiera del P. G. O. U., dadas las limitaciones de presupuestos ordinarios y extraordinarios para inversiones reales. Por ello deberían formarse equipos municipales de seguimiento del Plan y de su gestión financiera.

Es importante consolidar una auténtica autonomía municipal en la disciplina urbanística, sin menoscabo de las competencias del Estado y la Autonomía, dada la importancia de las inversiones generales: energética, hidráulica, transportes, comunicaciones, etc. que gravitan sobre la ciudad.

Con referencia al sector inmobiliario habrá que establecer pautas que dinamicen el mercado del suelo de modo que los propietarios oferten la superficie requerida en el P. G. O. U. para la armonización de usos prevista. 
Habrá de configurarse un modelo de promotor y/o constructor que responda a las exigencias de usuarios menos rígidos en sus demandas que los actuales, para los que sería preciso abrir una vía de escape a su acumulación de necesidad e insolvencia mediante una adecuada política de rentas en el sistema de alquileres y programas de ayuda y subvenciones para la rehabilitación de inmuebles.

Debe fomentarse la participación ciudadana de las asociaciones de vecinos, por la inmediatez con que sufren estos los efectos de la ciudad. Pero a su vez debe llevarse a cabo una sistemática tarea de formación sobre los valores comunitarios de la urbanidad y el respeto general a las reglas del juego.

A los urbanistas debe exigírseles el abandono de las prácticas de aplicación del modelo estructural macroscópico y el racionalismo y una aplicación más intuitiva en la resolución de los problemas. Éstos deberán preocuparse más de la valoración del patrimonio urbano y del medio ambiente que de «construir» nuevos espacios urbanos, a la vez que deberán evitar la «muerte clínica» del centro histórico.

Por ello, parece razonable plantear, en relación con el área metropolitana, la constitución de una entidad capaz de resolver los problemas administrativos de tipo institucional a los que la demanda social aspira en este aspecto. Dicho organismo debería entrar en la consideración del principal problema metropolitano, el de las comunicaciones dentro del área, que no puede seguir siendo contemplado desde una fragmentaria doble óptica alicantino-ilicitana, o desde organismo extramunicipales, como el M.O.P.U., dado el proceso de cambios que en la tendencia de los flujos generará la construcción de la autovía Alicante-Murcia, a la que habrá que añadir la de Alicante-Cartagena, que producirán la apertura de nuevas calles, la urbanización creciente o la construcción de nuevas y grandes superficies comerciales, sin olvidar, finalmente, los efectos suprametropolitanos (Benidorm, aeropuerto) de las mismas. Por ello, es absolutamente imprescindible planificar las repercusiones futuras de decisiones de este tipo.

Otro elemento infraestructural necesitado de replanteamiento es el de los sistemas ferroviarios. Deben dejar de analizarse como un impacto obstaculizador del desarrollo particular de cada ciudad para concebirse como un imprescindible elemento nexual con el sistema de transporte por carretera y el aeropuerto. Para ello, debería asegurarse un fácil y poco costoso enlace con éste último y acaso una estación-depósito general de mercancías común para ambas.

En idéntico sentido habría que plantear, en el futuro, la continuación del trazado ferroviario de FEVE, hasta conectar con el de RENFE y el aeropuerto. Con ello cambiaría y mejoraría extraordinariamente el sistema de comunicaciones con el tramo costero septentrional, con evidentes repercusiones en el transporte público de taxis y autobuses, especialmente con relación a Benidorm.

Debería ser común también, el área de los servicios tales como el abastecimiento y el reaprovechamiento del agua. El abastecimiento mediante la Mancomunidad de Canales del Taibilla, o las procedentes de Villena, existente en la actualidad, podría verse incrementado y asegurado con un menor coste en cuanto se estableciera en común para el área metropolitana.

Por su parte, es necesario planificar en común los programas de depuración de alcantarillado costero de Urbanova y arenales del Sol, así como el reaprovechamiento para el riego de sus aguas. Igualmente, el tratamiento de los residuos urbanos, dado el tamaño de la aglomeración, debería incluirse en este esquema de actuación. 
Otro tipo de servicios, de costosa construcción y mantenimiento, pero absolutamente necesarios, son aquéllos que requieren un umbral mínimo de utilización. Podrían ser algunos dedicados a deportes de especialización atlética, pistas de ciclismo, o sanitarios de atención a las toxicomanías, aulas de rehabilitación de minusválidos, servicios medioambientales, etc.

No obstante todas estas propuestas de metropolitanización futura no pueden olvidar los efectos inhibidores que a la prestación de servicios fundamentales introduce la proyección futura de la actual coyuntura económica, acerca de la cual habrá que definir y fijar futuras estrategias correctoras.

Por otra parte, dado que el área metropolitana de Alicante-Elche no presenta únicamente elementos de properidad, altas rentas y eficiente actividad económica, sino que en la misma aparecen también como efectos de crisis económica, un importante nivel de desempleo así como la consiguiente marginación social, urge arbitrar las correspondientes medidas correctoras.

En efecto, el paro afecta a una considerable proporción de los activos del área. Prácticamente la mitad de los 100.000 parados provinciales se ubican aquí, con cantidades similares en ambas subzonas, ya que la crisis aún incidiendo específicamente en la industria del calzado y auxiliares de Elche, ha afectado igualmente a Alicante.

La especificidad sectorial de los principales núcleos de población exige medidas diferentes, al ser distintas sus problemáticas. Alicante, orientada al sector terciario, servicios, comercio y administración mantiene algunos sectores industriales en declive. Por ello presenta las características propias de una zona en profunda renovación de su sistema productivo, configurándose como centro metropolitano, al que su rango administrativo de capital desborda, exigiéndole servicios centrales de rango provincial, al tiempo que afianza la actividad turística.

En Elche la adaptación a la crisis ha supuesto el desarrollo de formas de producción industrial, específicamente intensas en las gamas del calzado, caracterizadas por el desarrollo del trabajo a domicilio en un sistema de clandestinaje económico que afecta el $50 \%$ de la capacidad productiva y del empleo ilicitanos. El conocimiento de este peculiar modo de producción y de sus efectos debe ser el punto de partida en la búsqueda de alternativas y soluciones de la crisis.

En ambas subáreas, además de la proximidad geográfica, aparecen condiciones muy favorables para la solución conjunta de los nuevos problemas inherentes a la promoción económica. Existe también contrastada capacidad de iniciativa, infraestructuras de comunicación y ambiente favorable, así como disponibilidad de centros universitarios que asociados a la base económica del territorio podrían asegurar el éxito de cualquier tipo de iniciativa articuladora de esta problemática.

Sin olvidar, finalmente, que las empresas de tecnología y servicios de punta o avanzados, disponen de condiciones inmejorables para su instalación, así como para la posibilidad de difusión de sus avances en el entorno, en el que la ubicación de nuevos polígonos industriales, residenciales, científicos y de ocio tendrían armónica acogida y a través de los mismos sería posible potenciar manifestaciones feriales, encuentros científicos y nuevas ofertas de servicios complementarios, de forma que al iniciarse el siglo XXI el territorio apuntase los signos de una dinámica de modernización, ya que no es pensable una espectacular modificación de las actuales tendencias económicas. 